\title{
Immobilization of Sulfur from Different Precursors on Mini Rice-Husk-Ash Pellet Coated Chitosan Film and the Application for Mercury Vapor Uptake
}

\author{
Muhammad Adlim ${ }^{1, *}$, Fitri Zarlaida ${ }^{1}$, Ibnu Khaldun', Rizka Dewi ${ }^{1}$, \\ Sofyatuddin Karina ${ }^{2}$, and Ahmad Fairuz Omar ${ }^{3}$ \\ ${ }^{1}$ Department of Chemistry, FKIP, Syiah Kuala University, \\ Jl. Tgk. Hasan Krueng Kalee Darussalam Banda Aceh, Aceh 23111, Indonesia
}

${ }^{2}$ Marine Science Department, Faculty of Fisheries and Marine Sciences, Syiah Kuala University, Jl. Teuku Nyak Arief, Darussalam Banda Aceh, Aceh 23111, Indonesia

${ }^{3}$ School of Physical Sciences, Universiti Sains Malaysia, Minden, Penang 11800, Malaysia

\section{* Corresponding author:}

tel: $+62-8126300046$

email:adlim@unsyiah.ac.id

Received: April 5, 2018

Accepted: July 20, 2018

DOI: $10.22146 /$ ijc. 34552

\begin{abstract}
Stabilizing elemental mercury using elemental sulfur has been a laboratory standard method but the studies in gas system are still growing. This study aims to explore the effect of different type immobilized sulfurs toward the mercury vapor uptake in a mini gas reactor. Hypothetically, different type of sulfur might give different particle aggregation. Sulfur powder, sulfur dissolved in carbon disulfide and colloidal sulfur from sodium thiosulfate-hydrochloric acid were immobilized on mini rice-husk-ash pellets that

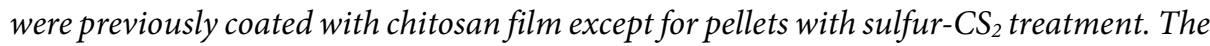
average thickness of chitosan film was $58 \mu \mathrm{m}$ covered the each pellet surface with dimension of $3 \mathrm{~mm} \varnothing \times 4 \mathrm{~mm}$. The trends of the mercury uptake and the rate of absorption were described as follow; Pellet- $S_{\text {colloid }}>$ Pellet- $S_{C S 2}>$ Pellet- $S_{\text {powder. }}$ The mean percentages of mercury uptake after $1 \mathrm{~h}$ running at $70{ }^{\circ} \mathrm{C}$ were 99.36; 89.09 and 75.00, respectively. The reverse trends were observed for the size of S-particle aggregation and the amount of $S$ found on the pellet surface.
\end{abstract}

Keywords: chitosan; rice husk ash; HgS; colloidal sulfur; impregnation

\section{- INTRODUCTION}

Mercury and its compounds are among the most toxic in heavy metal groups. Most of mercury releases to atmosphere in the form of elemental mercury vapor as a flue gas from amalgam and coal burning [1]. The mercury backs to the earth; it is oxidized to mercury ions, accumulated by biomass [2] and finally enters the food chain.

Several recent studies on risk reduction of mercury pollution have been reported in literature. Mercury vapor was usually trapped by using active carbon, or other sorbent containing noble metals or copper salt [3-5]. Absorption without stabilization of mercury made the concern on the toxicity [6]. Thereby it is preferable to convert mercury vapor to $\mathrm{HgS}$ which is much less toxic than other mercury species [7]. Theoretically, reaction between sulfur powder and elemental mercury at $60^{\circ} \mathrm{C}$ forms metacinnabar ( $\mathrm{HgS}$ ) and it becomes a standard procedure in laboratory and industrial mercury waste treatment [8-9]. In fact, without any additional treatment, the reaction was very slow [10]. Studies on how to accelerate the reaction and reaction in a gas system are still growing.

Using sulfur powder for stabilizing mercury vapor in a continuous gas reactor is considered ineffective since sulfur particles will block the vapor stream. Therefore, impregnation of sulfur powder on a solid support such as carbon was the alternative solution [11], but small carbon particles could also inhibit the gas flow. The reaction rate between elemental mercury with elemental sulfur immobilized on granular carbon was only fast at elevated temperature $\left(140-600{ }^{\circ} \mathrm{C}\right)$ [12-13]. 
With this operational condition, sulfur (the melting point: $115.2^{\circ} \mathrm{C}$ ) tends to leach out from the support and it can induce particle aggregation, reduce the surface area, subsequently lessen the mercury uptake and plausibly block the vapor stream [13]. This study aims to introduce mini compatible pellets as the alternative support and preparation of immobilized elemental sulfur that is reactive for elemental mercury vapor at lower temperature condition.

Elemental sulfur as sulfur colloidal nanoparticles is usually prepared from sodium thiosulfate- $\mathrm{HCl}$ by using either surfactant as the stabilizer or by solvent exchange or by using thiol compounds as the precursor [14-16] or other methods [17]. However immobilization of elemental sulfur on chitosan film tailored onto rice-husk-ash pellet has not much been known, although chitosan has been known as a stabilizer and a template in the preparation immobilized colloidal metal nanoparticles on titania [1820]. Chitosan also has been proven to form a compatible film for wide applications [21-23]. This study aims to explore the effect of various immobilized sulfur on the mercury vapor uptake in a mini gas reactor.

\section{- EXPERIMENTAL SECTION}

\section{Materials}

Some research materials were including rice husk ash that pass through 200 mesh siever, elemental mercury (99\%, Merck); $\mathrm{Na}_{2} \mathrm{~S}_{2} \mathrm{O}_{3} \cdot 5 \mathrm{H}_{2} \mathrm{O}$ (p.a. Merck), $\mathrm{Na}_{2} \mathrm{~S} \cdot 9 \mathrm{H}_{2} \mathrm{O}$ (ACS, Fischer, 98\%), $\mathrm{KMnO}_{4}$ (p.a. Merck), $\mathrm{H}_{2} \mathrm{SO}_{4}$ (p.a. Merck), Chitosan medium molecular weight (Fluka), $\mathrm{CS}_{2}$ (ACS, Merck), mercury metal (> 99.6\%, Merck), purified sulfur powder (Merck) were purchased without further purification.

\section{Instrumentation}

Several analytical instrumentations were used for collecting data. Hitachi SU-3500 SEM and Horiba EDX equipment were used for pellet surface analysis. The measurement was at Vacc $20 \mathrm{kV}$ and spot intensity of 50 . This instrument was equipped with a BSE (Back-ScatterElectron) with 500-2500 times magnification for point analysis of inorganic elements. Torontech TT-EDXPRT XRF was used to analyze the chemical content of the samples. Philip CM 12 Electron Microscope was used for TEM micrograph to measure particle size. Atomic Absorption Spectrophotometry of Shimadzu AA-6300 equipped with mercury lamps was used to determine mercury retained on the pellets surface.

\section{Procedure}

\section{Pellet preparation}

Pellet (P) was prepared from rice husk ash (RHA) $(<200$ mesh) and polyvinyl acetate (PVA) as the adhesive material. The suitable composite composition with weight ratio of RHA:PVA: $\mathrm{H}_{2} \mathrm{O}$ was $7: 2: 1$. The composite was mixed using a blender, then inserted into holes of pellet dies ( $3 \mathrm{~mm}$ diameter holes, $4 \mathrm{~mm}$ height). It was pressed with a hydraulic press machine at 0.5 tones before heating at $50{ }^{\circ} \mathrm{C}$ and dried for $24 \mathrm{~h}$. Dried pellets were immersed for $48 \mathrm{~h}$ in $200 \mathrm{~mL}$ distilled water to test the decomposition resistance in water.

\section{Sulfur immobilization onto the pellet surfaces}

Elemental sulfurs from three types of precursors were immobilized onto pellet surfaces. Pellets (150 g) that have relatively uniform shape were divided in two glass Beakers; $50 \mathrm{~g}$ and $100 \mathrm{~g}$ for preparation.

Pellet'surface covered with $\mathbf{S}$ from $\mathrm{CS}_{2}$ solution ( $\mathrm{P}$ $\left.\mathbf{S}_{\mathrm{Cs} 2}\right)$. Dried pellets $(50 \mathrm{~g})$ were dipped $2 \mathrm{~min}$ in a saturated cold solution of sulfur- $\mathrm{CS}_{2}(100 \mathrm{~mL})$ then, the pellets were filtered and air dried for $2 \mathrm{~h}$.

Pellet covered with S powder (P-Spowder). Another $100 \mathrm{~g}$ of dried pellets were placed in a plastic siever and dipped into chitosan solution $(0.6 \mathrm{~g}$ chitosan in $100 \mathrm{~mL}$ of $1.5 \%$ acetic acid) until all were wet, filtered and air dried for $3 \mathrm{~h}$ denoted as $\left(\mathrm{P}_{\text {chitosan }}\right)$. This chitosan coating technique was verified by the previous methods [19]. Half portion of $\mathrm{P}_{\text {chitosan }}(50 \mathrm{~g}) \mathrm{w}$ placed in a plastic sifter, dipped into 50\% methanol-water for $2 \mathrm{~min}$, filtered and transferred into a boiling flask containing $100 \mathrm{~g}$ sulfurpowder. The flask was rotated with a rotary evaporator until all pellets' surfaces were covered by sulfur powder. The treated pellets were placed a plastic siever, dried in an oven at $70{ }^{\circ} \mathrm{C}$ and flashed out the excessive sulfur using a blower.

Pellet covered with $\mathbf{S}$ from sulfur colloid ( $\left.\mathbf{P}-\mathrm{S}_{\text {colloid }}\right)$. Fine particle sulfur might be obtained from the colloidal 


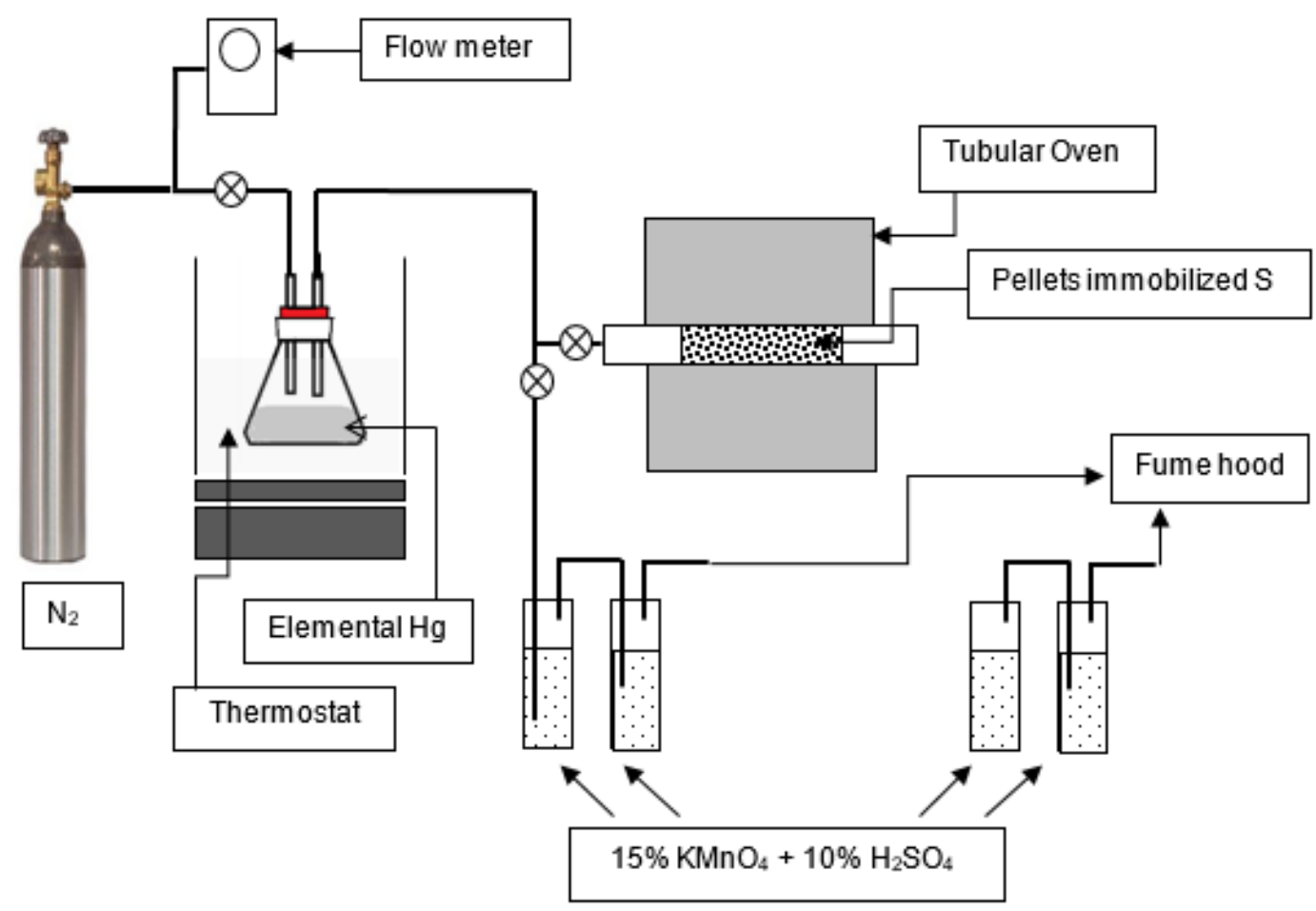

Fig 1. Diagram of mercury vapor stabilization experiment

sulfur analog to previous studies reported on nano material [21]. Sulfur was prepared from the colloidal solution of sodium thiosulfate- $\mathrm{HCl}$ and subsequently immobilized onto the surface of the pellet as follow: Another half portion of $\mathrm{P}_{\text {chitosan }}(50 \mathrm{~g})$ was placed in a plastic sifter and dipped in water-methanol (50:50) before shook gently and sprayed with $2 \mathrm{M}$ of $\mathrm{Na}_{2} \mathrm{~S}_{2} \mathrm{O}_{4} \cdot 5 \mathrm{H}_{2} \mathrm{O}$ solution until all part of pellets were wet. The pellets were separated and dried in an oven at $60^{\circ} \mathrm{C}$ for $1 \mathrm{~h}$. Each type of pellets ( $a, b$ and $c)$ was placed on each plastic strainer then were carefully sprayed with $4 \mathrm{M} \mathrm{HCl}$ solution until all were wet and air dried for $10 \mathrm{~min}$ then dried again in the oven at $70{ }^{\circ} \mathrm{C}$ until constant weight. The pellets were sampled and soaked in $5 \mathrm{ml}$ of distilled water and monitored the $\mathrm{pH}$. If the $\mathrm{pH}<5$ then, the pellets were washed carefully with distilled water by decantation several times and dried again in an oven until constant weight. The formation of sulfur colloids from sodium thiosulfate was verified the reported method [24]. All types of pellets ( $a, b$ and $c$ ) were sprayed with $1 \%$ of $\mathrm{Na}_{2} \mathrm{~S}$ solution and air dried for $10 \mathrm{~min}$ and kept in an oven at $70{ }^{\circ} \mathrm{C}$ for $24 \mathrm{~h}$.
The amount of sulfur on the surface of pellets was characterized by using XRF [25] and by gravimetric methods. The pellets containing sulfur was extracted by using cold $\mathrm{CS}_{2}$ to dissolve the sulfur. $\mathrm{CS}_{2}$ is the solvent that dissolves the high amount of elemental sulfur [26]. The filtrate was evaporated off and the residue was weighted using an analytical balance. Prior to XRF analysis, sample was prepared by the instrument procedure including heating and vacuum drying.

\section{Experimental set up for stabilizing mercury vapor}

The experimental set up (Fig. 1) was modified from previous study [27]. The sulfur-immobilized pellets were dried at $105^{\circ} \mathrm{C}$ until constant weight, then cooled down. Each type of pellets was filled up into a glass cylinder reactor and covered the area of $10 \mathrm{~cm}$ length and $1 \mathrm{~cm}$ diameter. The average amount of each type of pellets inside the reactor was $3.144 \pm 0.4 \mathrm{~g}$. Elemental mercury was heated in a closed Erlenmeyer and placed in a water bath equipped with a thermostat that maintained at $70{ }^{\circ} \mathrm{C}$ as displayed in Fig. 1. Nitrogen gas was flushed through the mercury surface without bubbling with flow 


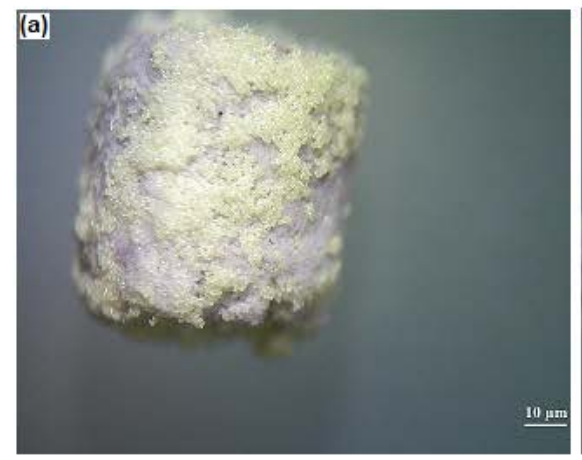

Fig 2. The pellet surface; image of immobilized sulfur; (a) P-
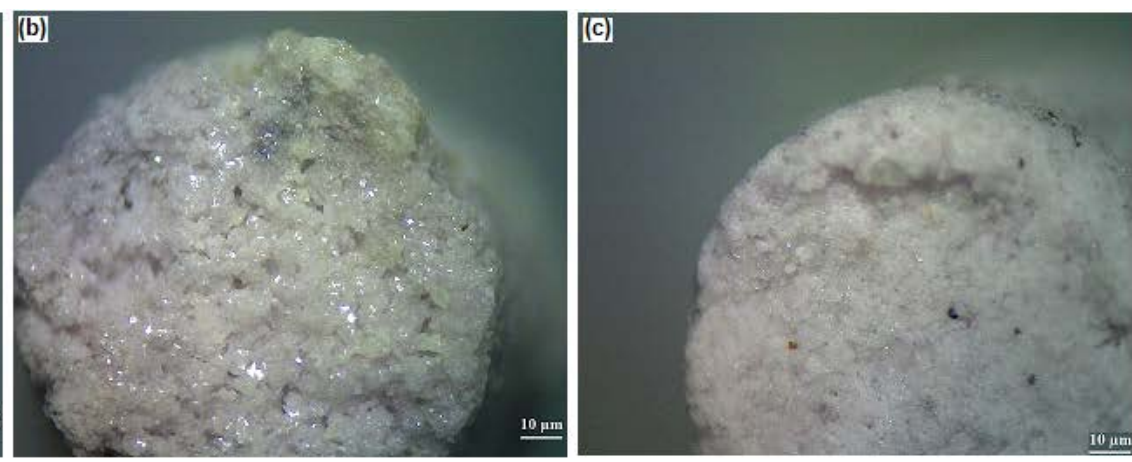

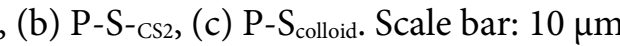

rate of $350 \mathrm{~mL} / \mathrm{min}$ to obtain natural vapor of hot elemental mercury. The temperature of reactor was maintained at $70{ }^{\circ} \mathrm{C}$ in a tubular oven. The nitrogen flew in experimental line was stopped at time interval of 20,40, $60 \mathrm{~min}$. At every interval time, the used pellets were replaced with fresh ones. The experiment was repeated for different type of sulfur-immobilized pellets.

The mercury waste that was not absorbed by treated pellets was bubbled into $\mathrm{KMnO}_{4}-\mathrm{H}_{2} \mathrm{SO}_{4}$ solution (10 g $\mathrm{KMnO}_{4}$ was dissolved in $250 \mathrm{~mL}$ of $10 \% \mathrm{H}_{2} \mathrm{SO}_{4}$ solution).The mercury uptake on the pellet was analyzed using CV-AAS methods. About $2 \mathrm{~g}$ of mercury absorbed pellets from each experiment were added $10 \mathrm{~mL}$ of aqua regia and slowly heated in a water bath until the volume reduced to about $2 \mathrm{~mL} .10 \mathrm{~mL}$ distillated water was added into the residue, filtered and transferred into a volumetric flask and diluted with distillated water until $25 \mathrm{~mL}$. This solution and the trapped solution were also taken for CVAAS (Cold Vapor-Atomic Absorption Spectrophotometry) analysis for each experiment.

Mercury absorbed pellets were also analyzed using TEM, EDX and XRF. For TEM analysis, mercury absorbed pellets were suspended in $1.5 \%$ aqueous acetic acid to swell the chitosan coating and subsequently released sulfur and $\mathrm{HgS}$ from the surface into the solution and become a suspension. Then a drop of the suspension was placed onto a carbon grid before taking the TEM image verified previous method [28-29]. For SEM-EDX and XRF analysis, the treated pellets were previously dried until constant weight.

Mercury uptake was determined from the amount mercury found on the pellet surface. The mercury retention was calculated by a comparison between amount of mercury uptake and the total amount of mercury vapor. The total amount mercury vapor was the sum of mercury uptake and mercury trapped in $\mathrm{KMnO}_{4}$ $\mathrm{H}_{2} \mathrm{SO}_{4}$ after the mercury stream pass through the pellet.

\section{- RESULTS AND DISCUSSION}

\section{Pellet Characterization}

The right proportion of RHA, PVA and water affected the pellet performance. Dried pellets were a cylinder like shape with dimension of $3 \mathrm{~mm}$ diameter and $4 \mathrm{~mm}$ length and stable in water for at least $48 \mathrm{~h}$. With this stability characteristics made the sulfur immobilization process achievable and the chitosan film thickness on surface of pellets was of 26-89 micron. Fig. $2(a-c)$ were part of confirmation for the feasibility of immobilization process. The sulfur particles were anchored on the surface of chitosan film analogizing the previously procedure on colloidal metal nanoparticle immobilization [20]. The mean of water content in each type of pellets was $16.17 \pm 0.7 \%$.

The microscope images for each type of pellets were presented in Fig. 2(a-c). At similar magnification, the yellowish and dense sulfur aggregation on the surface of mini pellets can be observed at Fig. 2(a). The color and the aggregation become lighter as seen in Fig. 2(b) and almost all white with smooth surface in Fig. 2(c). The dense aggregation was composed by large particle clusters (Fig. 2(a)). Smaller S particles tended to penetrate the pellets pore and caused less particle aggregation in surface of pellets. It represented as yellowish and white S particles (Fig. 2(b-c)). Since S was 
dissolved in CS2 which is very volatile then S particle quickly aggregated and assembled a yellowish sulfur layer (Fig. 2(b)). Apparently this phenomenon did occur for sulfur colloids from aqueous inorganic salt as represented light yellowish or nearly white color of sulfur particles. Thereby, it is rational to predict that the particle size of sulfur followed the trend of $\mathrm{P}-\mathrm{S}_{\text {powder }}>\mathrm{P}-\mathrm{S}_{\mathrm{CS} 2}>\mathrm{P}-\mathrm{S}_{\text {colloid. }}$. Bulky and aggregated sulfur particles were observed on $\mathrm{P}$ $\mathrm{S}_{\text {powder }}$ Smaller and sulfur particles were on $\mathrm{P}-\mathrm{S}_{\mathrm{CS} 2}$ and the finest and dispersed white sulfur particles were observed on $\mathrm{P}_{\text {- }}$ colloid $($ Fig. 2(c)). The size of individual sulfur colloid was predicted less than one micron verified the previous reported at different type of support [14].

Surface SEM images of pellet shown in Fig. 3(a-c) look consistent to light microscope image that the smaller particle fragments were observed on P-S $\mathrm{S}_{\text {colloid }}$ (Fig. 3(c)). The fragment size might have correlation with the particle cluster size and the roughness surface. The XRF data of sulfur was in form of $\mathrm{SO}_{3}$ which equaled to $\mathrm{S}$ content of $35.36,12$, and $1.172 \%$ following the trend of $\mathrm{P}-\mathrm{S}_{\text {powder }}>\mathrm{P}-$ $\mathrm{S}_{\mathrm{CS} 2}>\mathrm{P}-\mathrm{S}_{\text {colloid. }}$. The weight percentages $(\mathrm{wt} . \%)$ were relatively lower than theoretically predicted probably this is due to sulfur sublimation during analysis [25]. From the EDX spectrum randomly scanned on 25 points, the relative sulfur content was found the lowest in $\mathrm{P}-\mathrm{S}_{\text {colloid }}$ which was only $2.55 \mathrm{wt} . \%$ compared to $\mathrm{P}-\mathrm{S}_{\text {powder }}$ and $\mathrm{P}-\mathrm{S}_{\mathrm{CS} 2}$ that were 20.75 and 25.21 wt.\%, respectively. This trend was also consistent with gravimetric data that the lowest

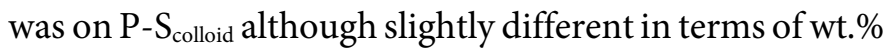
sulfur content. The EDX data showed that the smallest variance of wt.\% sulfur content on pellet surface was in $\mathrm{P}-\mathrm{S}_{\text {colloid }}\left(s^{2}=9.5\right)$. The larger data variances was found in $\mathrm{P}-\mathrm{S}_{\text {powder }}\left(s^{2}=1462.7\right)$ and smaller variance was in $\mathrm{P}-\mathrm{S}_{\mathrm{CS} 2}$ $\left(s^{2}=738.8\right)$. This might suggest that sulfur particles were
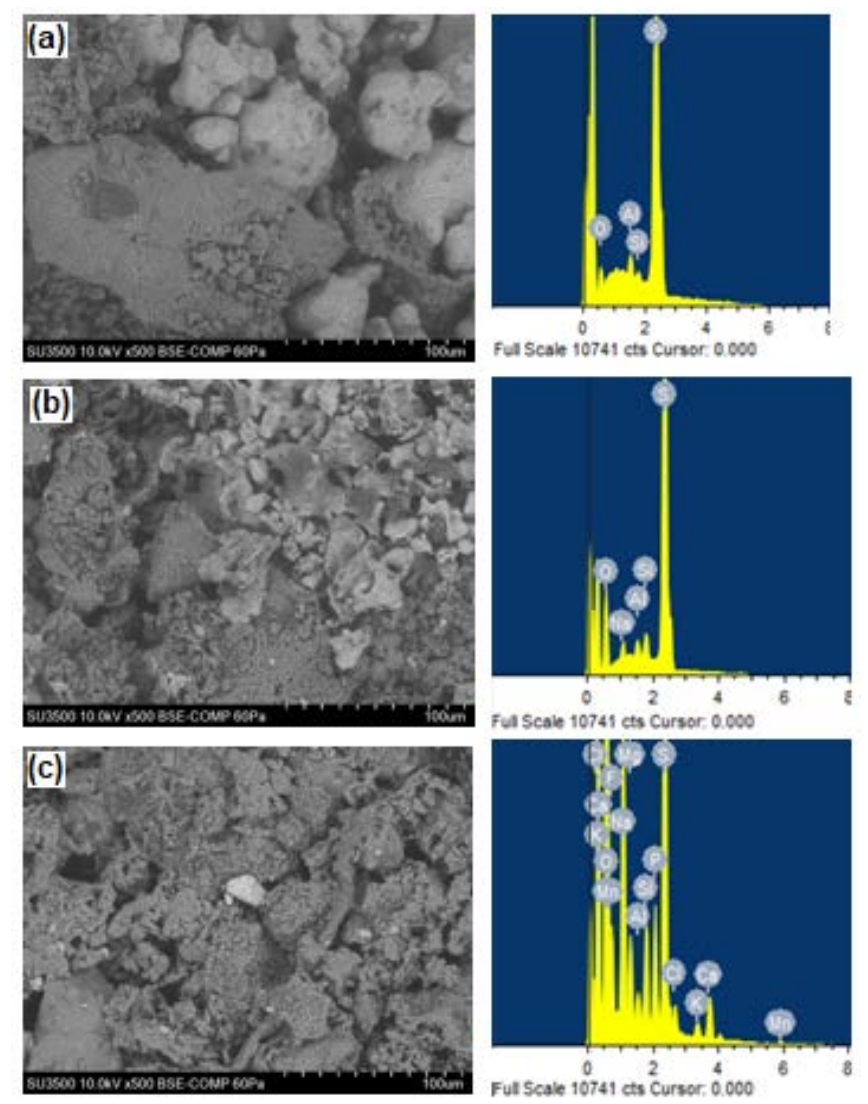

Fig 3. SEM of immobilized sulfur pellet surface (left) and EDX (right) of each pellets containing sulfur prepared from different precursor. (a) P-S powder, (b) P-S $\mathrm{S}_{\mathrm{CS} 2}$, (c) P$\mathrm{S}_{\text {colloid. }}$ Scale bar: $100 \mu \mathrm{m}$

Table 1. Mercury vapor retention on the pellets

\begin{tabular}{|c|c|c|c|c|c|c|c|c|c|}
\hline No & $\begin{array}{l}\text { Type of } \\
\text { Pellets }\end{array}$ & $\begin{array}{c}\text { Contact } \\
\text { times }(\mathrm{min})\end{array}$ & $\begin{array}{l}\text { Absorbed } \\
\mathrm{Hg}(\mathrm{ppm})\end{array}$ & $\begin{array}{c}\text { Trapped } \\
\text { Hg (ppm) }\end{array}$ & $\begin{array}{c}\text { Total Hg } \\
(\mathrm{ppm})\end{array}$ & $\begin{array}{c}\text { Hg uptake } \\
(\%)\end{array}$ & $\begin{array}{c}\text { S on } \\
\text { pellets }^{*}(\mathrm{~g}) \\
\end{array}$ & $\begin{array}{l}\text { Hg uptake per } \\
\text { g S (ppm/g S) }\end{array}$ & $\begin{array}{l}\text { Hg uptake per } \\
\text { ppm. } \mathrm{g}^{-1} \mathrm{~min}^{-1}\end{array}$ \\
\hline \multirow{3}{*}{1} & \multirow{3}{*}{$\mathrm{P}-\mathrm{S}_{\text {powder }}$} & 20 & 0.325 & 0.239 & 0.564 & 57.667 & 0.135 & 2.410 & 0.120 \\
\hline & & 40 & 0.851 & 0.325 & 1.176 & 72.368 & 0.133 & 6.420 & 0.160 \\
\hline & & 60 & 1.063 & 0.351 & 1.414 & 75.173 & 0.132 & 8.054 & 0.134 \\
\hline \multirow{3}{*}{2} & \multirow{3}{*}{$\mathrm{P}-\mathrm{S}_{\mathrm{CS} 2}$} & 20 & 0.705 & 0.119 & 0.825 & 85.518 & 0.068 & 10.369 & 0.518 \\
\hline & & 40 & 1.114 & 0.181 & 1.295 & 85.995 & 0.066 & 16.840 & 0.421 \\
\hline & & 60 & 1.251 & 0.153 & 1.404 & 89.095 & 0.070 & 17.869 & 0.298 \\
\hline \multirow{3}{*}{3} & \multirow{3}{*}{ P-S colloid $_{\text {}}$} & 20 & 0.981 & 0.050 & 1.031 & 95.148 & 0.014 & 70.036 & 3.502 \\
\hline & & 40 & 1.115 & 0.030 & 1.145 & 97.381 & 0.019 & 58.700 & 1.468 \\
\hline & & 60 & 1.551 & 0.010 & 1.561 & 99.36 & 0.016 & 96.963 & 1.616 \\
\hline
\end{tabular}

*data based on gravimetric methods 
more dispersed and in uniform size on the surface of $\mathrm{P}$ $\mathrm{S}_{\text {colloid }}$ than the others.

Fig. 3 displayed different number of trace elements within $\mathrm{P}-\mathrm{S}_{\text {powder }}$ P- $\mathrm{S}_{\mathrm{CS} 2}$ and $\mathrm{P}-\mathrm{S}_{\text {colloid. }}$. This has correlation with sulfur layer thickness on the surface of pellets. P$\mathrm{S}_{\text {powder }}$ that has more and dense sulfur particles (as shown in Fig. 2) shielded the electron beam for dipper scanning. Less number of trace elements was detected on P-S $\mathrm{S}_{\mathrm{CS} 2}$, P$\mathrm{S}_{\text {colloid }}$ having less sulfur but more dispersed sulfur particles. This let the electron beam penetrate the surface dipper and consequently more trace elements inside the pellet material were detected. The trace elements should not affect on the mercury uptake since the reactive site for mercury capture was only at the sulfur particles on the pellet surface as we confirmed in preliminary experiment.
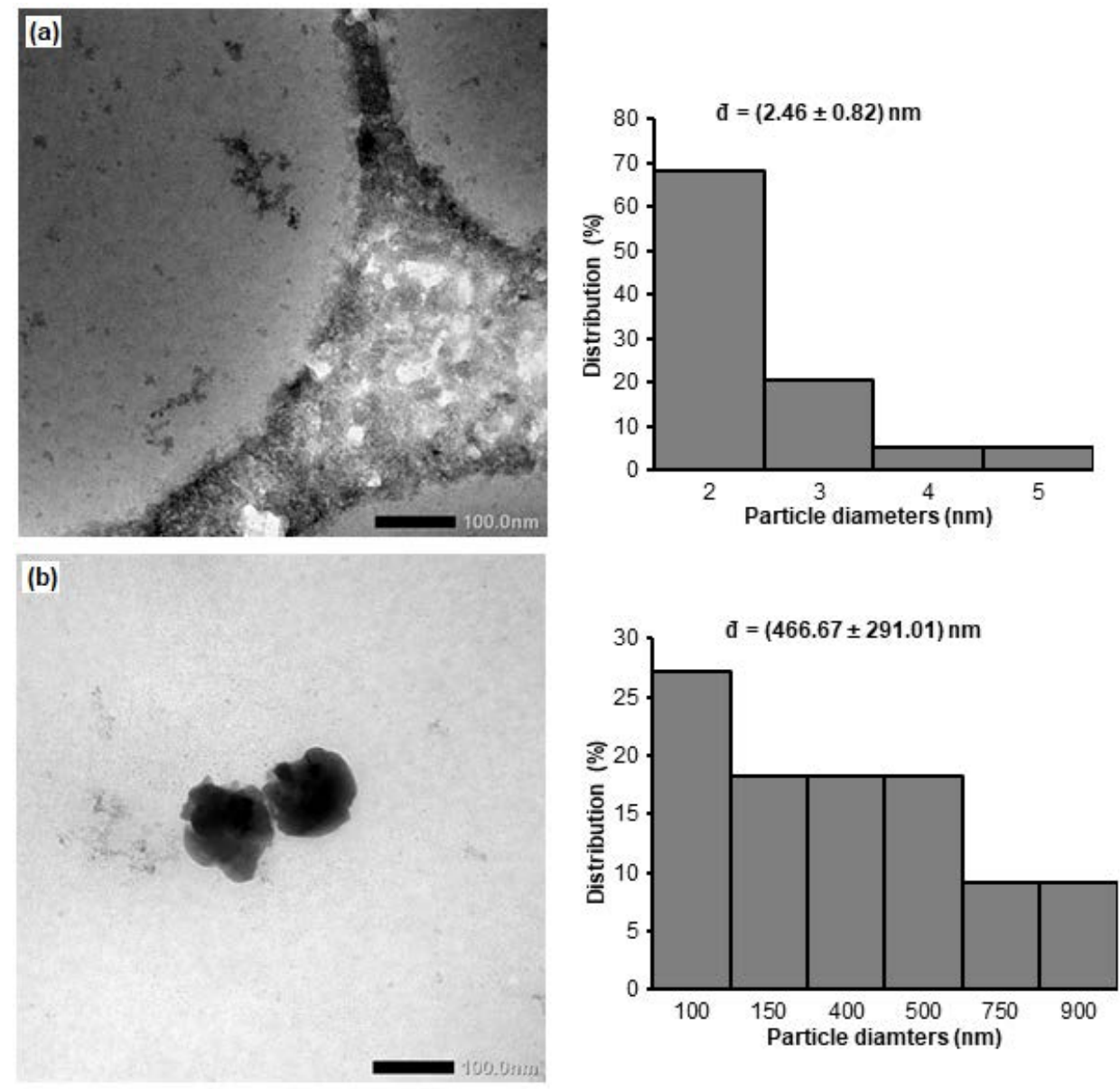

Fig 4. Preventative of TEM images and histogram particle size of (a) HgS on the surface of P-S-colloid, (b) P-S-powder. Scale bar: $100 \mathrm{~nm}$

\section{Mercury Vapor Uptake}

Before experiment of mercury stabilization was run in the gas reactor line, we had confirmed the stabilizing reaction of elemental mercury either power or colloidal sulfurs with and without $\mathrm{Na}_{2} \mathrm{~S}$. The existence of reaction indicated by the formation of a black matter (metacinnabar, $\mathrm{HgS}$ ) verified the previous reported [30].

Mercury vapor retained on each treated pellets/min was recorded from the experimental gas line and tabulated in Table 1. The mercury uptake increased with time but apparently it did not much affect by the amount of sulfur, instead it was significantly influenced by type of sulfur preparation and sulfur particle size. At similar weight of pellets, P-S-colloid had the lowest sulfur content but it gave the highest mercury retention.

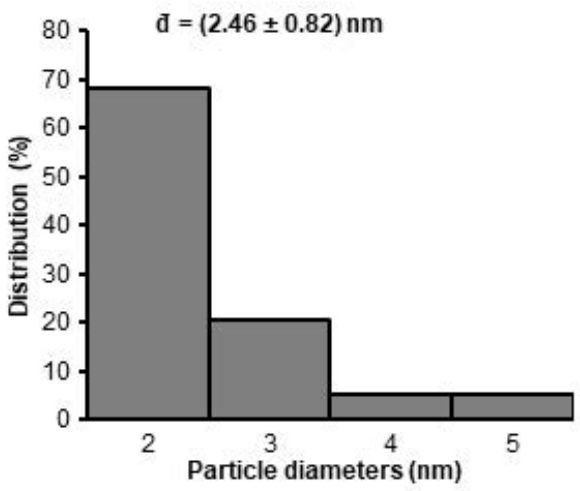


At $70{ }^{\circ} \mathrm{C}$, P-S-colloid retained up to $99.36 \%$ of mercury vapor while others were only $75.17 \%$ (on P-S $S_{\text {powder }}$ ) and 89.09\% (on $\mathrm{P}_{-} \mathrm{S}_{\mathrm{CS} 2}$ ) after $1 \mathrm{~h}$ of mercury vapor pass through these treated pellets. The highest mean rate of mercury vapor stabilization was recorded in $\mathrm{P}-\mathrm{S}_{\text {colloid }}$ that was $2.195 \pm 1.1 \mathrm{ppm} \mathrm{Hg}$ per gram $S$ per minute. There was significant differences of mercury uptake rate $\left(\mathrm{ppm}^{-1}\right.$, $\left.\mathrm{g}^{-1} \mathrm{~S}, \mathrm{~s}^{-1}\right)$ in pairs of pallets either P-S powder vs. P-S $\mathrm{CS}_{2}$ or P$\mathrm{S}_{\mathrm{CS} 2}$ Vs. P- $\mathrm{S}_{\text {colloid }}$ or P-S $\mathrm{S}_{\text {powder }}$ Vs $\mathrm{P}-\mathrm{S}_{\text {colloid }}$ with $\mathrm{t}_{\text {stat }}$ of $4.04,2.94$ and 3.10 at each $(\mathrm{P}=0.05, \mathrm{df}=2)$ respectively. Higher mercury uptake had correlation with the particles size of sulfur as described above; the smaller and dispersed particles gave larger surface area. $\mathrm{P}-\mathrm{S}_{\text {colloid }}$ having finest and dispersed particles presented the highest mercury uptake. The mercury uptake in this study at $70{ }^{\circ} \mathrm{C}$ was comparable to previous publication in which sulfur was immobilized on carbon with the operating temperature between $90-150{ }^{\circ} \mathrm{C}[13]$.

The evidence of stabilizing mercury vapor in an experimental gas line was deduced from TEM images of pellets and the mercury uptake. This technique verified the earlier report that $\mathrm{HgS}$ formation could be observed even under an optical microscope [31-32]. TEM images shown Fig. 4 displayed the particles of RHA and colloidal sulfur were both white and large while $\mathrm{HgS}$ particles were

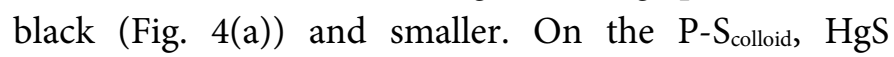
particles had mean diameter of $2.46 \mathrm{~nm}$ and very small size distribution. The larger $\mathrm{HgS}$ particles were observed on $\mathrm{P}-\mathrm{S}_{\text {powder }}$ (Fig. 4(b)) where the size of particle cluster was $466.67 \mathrm{~nm}$ and very large size deviation $(\mathrm{SD}=291$ $\mathrm{nm}$ ). This TEM data were also consistent with light microscope images (Fig. 2(b-c)) and SEM-EDX data (Fig. $3(\mathrm{a}-\mathrm{c})$ ) where $\mathrm{P}-\mathrm{S}_{\text {colloid }}$ apparently had smaller particles compared to $\mathrm{P}-\mathrm{S}_{\text {powder. }}$ TEM for P-S $\mathrm{S}_{\mathrm{CS} 2}$ was not available since the sulfur particles were not easily extracted into water during TEM sample preparation.

\section{- CONCLUSION}

Appropriate formula for RHA cylindrical pellets with dimension of $3 \mathrm{~mm} \emptyset \times 4 \mathrm{~mm}$ induced the durability in water at least for $48 \mathrm{~h}$ without decomposition. This stability characteristic made the immobilization of sulfur on the surface pellets practicable. Using chitosan as an adhesive and a stabilizer for sulfur particle onto the pellet surface let to anchor sulfur particles onto surface of pellet. The thickness of chitosan coating on pellets was average of 58 micron. Colloidal sulfur immobilized onto RHA pellets prepared from thiosulfate precursor had smaller particles and higher mercury uptake than those prepared from sulfur powder. Sulfur colloidal nanoparticles on RHA pellets retained mercury vapor up to $99.36 \%$ with rate of mercury uptake of $2.195 \pm 1.1$ ppm Hg per gram S per minute.

\section{- ACKNOWLEDGMENTS}

This research funded by research grant from Ministry of Research, Technology and Higher Education, Republic of Indonesia with grant registration number of "Penelitian Unggulan Perguruan Tinggi" 121/UN11.2/PP/SP3/2016.

\section{- REFERENCES}

[1] Shim, H.S., Jeong S.H., Kim, K.Y., and Lee S.S., 2012, Speciation of mercury in coal and sludge combustion flue gases, Environ. Prot. Eng., 38 (4), 77-85.

[2] Sitarska, M., Traczewska, T.M., Stanicka-Łotocka, A., Filyarovskaya, V., and Wojdyła, D.Z., 2014, Accumulation of mercury in the biomass of selected pleustophytes, Environ. Prot. Eng., 40 (1), 165-174.

[3] Huawei, Z., Xiuli, L., Li, W., and Peng, L., 2014, Characteristics and stability of mercury vapor adsorption over two kinds of modified semicoke, Sci. World J., 2014, 260141.

[4] Zhang, J., Duan, Y., Zhou, Q., Zhu, C., She, M., and Ding, W., 2016, Adsorptive removal of gas-phase mercury by oxygen non-thermal plasma modified activated carbon, Chem. Eng. J., 294, 281-289.

[5] Liu, Z., Li, X., Lee, J.Y., and Bolin, T.B., 2015, Oxidation of elemental mercury vapor over $\gamma-\mathrm{Al}_{2} \mathrm{O}_{3}$ supported $\mathrm{CuCl}_{2}$ catalyst for mercury emissions control, Chem. Eng. J., 275, 1-7.

[6] Lopez-Anton, M.A., Fernández-Miranda, N., and Martínez-Tarazona, M.R., 2016, The application of regenerable sorbents for mercury capture in gas phase, Environ. Sci. Pollut. Res., 23 (24), 24495-24503. 
[7] Huang, C.F., Hsu, C.J, Liu, S.H., and Lin-Shiau, S.Y., 2012, Exposure to low dose of cinnabar (a naturally occurring mercuric sulfide $(\mathrm{HgS})$ caused neurotoxicological effects in offspring mice, $J$. Biomed. Biotechnol., 2012, 254582.

[8] Lee, K.J., and Lee, T.G., 2012, A review of international trends in mercury management and available options for permanent or long-term mercury storage, J. Hazard. Mater., 241-242, 1-13.

[9] Rodríguez, O., Padilla, I., Tayibi, H., and LópezDelgado, A., 2012, Concerns on liquid mercury and mercury-containing wastes: A review of the treatment technologies for the safe storage, J. Environ. Manage., 101, 197-205.

[10] Devasena, M., and Nambi, I.M, 2013, In situ stabilization of entrapped elemental mercury, $J$. Environ. Manage., 130, 185-191.

[11] Hsi, H.C., and Chen, C.T., 2012, Influences of acidic/oxidizing gases on elemental mercury adsorption equilibrium and kinetics of sulfurimpregnated activated carbon, Fuel, 98, 229-235.

[12] Mullett, M., Pendleton, P., and Badalyan, A., 2012, Removal of elemental mercury from Bayer stack gases using sulfur-impregnated activated carbons, Chem. Eng. J., 211-212, 133-142.

[13] Reddy, K.S.K., Al Shoaibi, A., and Srinivasakannan, C., 2014, Gas-phase mercury removal through sulfur impregnated porous carbon, J. Ind. Eng. Chem., 20 (5), 2969-2974.

[14] Chaudhuri, R.G., and Paria, S., 2011, Growth kinetics of sulfur nanoparticles in aqueous surfactant solutions, J. Colloid Interface Sci., 354 (2), 563-569.

[15] Jia-jia, C., Jia, X., She, Q., Wang, C., Zhang, Q., Zheng, M., and Dong, Q., 2010, The preparation of nano-sulfur/MWCNTs and its electrochemical performance, Electrochim. Acta, 55 (27), 8062-8066.

[16] Makkuni, A., Bachas, L.G., Varma, R.S., Sikdar, S.K., and Bhattacharyya, D., 2005, Aqueous and vapor phase mercury sorption by inorganic oxide materials functionalized with thiols and poly-thiols, Clean Technol. Environ. Policy, 7, 87-96.

[17] Suleiman, M., Al Ali, A., Hussein, A., Hammouti, B., Ben Hadda, T., and Warad I., 2013, Sulfur nanoparticles: Synthesis, characterizations and their applications, J. Mater. Environ., Sci., 4 (6), 1029-1033.

[18] Adlim, and Bakar, M.A., 2008, Preparation of chitosan-gold nanoparticles: Part 2. Effect of reducing technique, Indones. J. Chem., 8 (3), 320326.

[19] Adlim, and Bakar, M.A., 2008, Preparation of chitosan-Gold nanoparticles: Part 1: Effect of reducing technique, Indones. J. Chem., 8 (2), 184188.

[20] Adlim, 2006, Immobilizing chitosan-stabilized palladium nanoclusters on titanium dioxide and their catalytic hydrogenation properties, JMS, 11, 125-133.

[21] Mahatmanti, F. W., Nuryono, and Narsito, 2014, Physical characteristics of chitosan based film modified with silica and polyethylene glycol, Indones. J. Chem., 14 (2), 131-137.

[22] Hastuti, B., Mudasir, Siswanta, D., and Triyono, 2015, Preparation and $\mathrm{Pb}(\mathrm{II})$ adsorption properties of crosslinked pectin-carboxymethylchitosan film, Indones. J. Chem., 15 (3), 248-255

[23] Tanjung, F.A., Arifin, Y., Abdullah, A.H., and Tahir, I., 2017, Bilayer-structured regenerated cellulose/chitosan films prepared with ionic liquid, Indones. J. Chem., 17 (3), 351-359.

[24] Chaudhuri, R.G., and Paria, S., 2010, Synthesis of sulfur nanoparticles in aqueous surfactant solutions, J. Colloid Interface Sci., 343 (2), 439-446.

[25] Chinchon, J.S., Lopez-Soler, A., Traveria, A., and Vaquer, R., 1988, X-ray fluorescence analysis of samples with elemental sulphur. Effect of sulphur sublimation, X-Ray Spectrom., 17 (6), 217-218.

[26] Ahmad, M., In which organic solvent is suitable for sulfur?, https://www.researchgate.net/post/In_which _organic_solvent_is_suitable_for_sulfur, accessed on 13 December 2017.

[27] Luo, J., Hein, A.M., and Hwang, J.Y., 2004, Adsorption of vapor phase mercury on various carbons, J. Miner. Mater. Charact. Eng., 3 (1), 13-22.

[28] Adlim, M., and Bakar, M.A., 2013, The properties of Pd/Au bimetallic colloidal catalysts stabilized by 
chitosan and prepared by simultaneous and stepwise chemical reduction of the precursor ions, Kinet. Catal., 54 (5), 586-596.

[29] Adlim, M., Bakar, M.A., Liew, K.Y., and Ismail, J., 2004, Synthesis of chitosan-stabilized platinum and palladium nanoparticles and their hydrogenation activity, J. Mol. Catal. A: Chem., 212 (1-2), 141-149.

[30] Ravichandran, M., Aiken, G.R., Ryan, J.N., and Reddy, M.M., 1999, Inhibition of precipitation and aggregation of metacinnabar (mercuric sulfide) by dissolved organic matter isolated from the Florida
Everglades, Environ. Sci. Technol., 33, 1418-1423.

[31] Lopez, F.A., Alguacil, F.J., Roman, C.P., Tayibi, H., and Delgano, Al., 2008, Disposal of elemental mercury via sulphur reaction by milling, Proceeding $1^{\text {st }}$ International Conference on Hazardous Waste Management, 1-3 October 2008; Chaina, Greece, 1-7.

[32] López, F.A., Padilla, I., Tayibi, H., and Alguacil, F.J., 2010, Formation of metacinnabar by milling of liquid mercury and elemental sulfur for long term mercury storage, Sci. Total Environ., 408 (20), 4341-4345. 